\title{
Modeling the relationship between carbon emissions and environmental sustainability during COVID-19: a new evidence from asymmetric ARDL cointegration approach
}

\author{
Muddassar Sarfraz ${ }^{1} \cdot$ Muhammad Mohsin $^{2} \cdot$ Sobia Naseem $^{3} \cdot$ Amit Kumar $^{4}$ (D)
}

Received: 12 January 2021 / Accepted: 2 March 2021 / Published online: 24 March 2021

(c) The Author(s), under exclusive licence to Springer Nature B.V. 2021

\begin{abstract}
The study aims to examine the $\mathrm{CO}_{2}$ emissions by considering the implication of COVID19 under strict lockdown in India. The nonlinear (asymmetric) relationship is investigated between $\mathrm{CO}_{2}$ emission and COVID-19 with its specific determinants. The positive and negative asymmetries of COVID-19 determinants are also captured by using econometric techniques. The daily data series of $\mathrm{CO}_{2}$ emission, new confirmed cases, confirmed deaths, and lockdown as dummy variables from January 30, 2020, to December 1, 2020, for India is analyzed by employing the nonlinear autoregressive distributed lag model. This research revealed a significant nonlinear relationship between $\mathrm{CO}_{2}$ emission and COVID-19. The bound test and asymmetric coefficients are confirmed by the variables' long- and short-run relationships. The dynamic multiplier graphs present that India's strict lockdown due to the rapid increase in COVID-19 patients significantly reduces toxic gas emissions, especially $\mathrm{CO}_{2}$ emissions. This asymmetric relationship has been proficiently declared that unhealthy public routine, extra traffic, and unhygienic gases released in the air become the reason for environmental destruction. The lockdown is practically imposed for specific periods and reasons, contributing to reducing toxic emissions, but it is not a permanent solution for environmental sustainability. The government of India, policymakers, and environmentalists should make people aware of unhealthy and environmentally envying activities and policies and long-term applicable strategies should be designed to upgrade the environment's quality.
\end{abstract}

Keywords $\mathrm{CO}_{2}$ emission $\cdot$ Sustainable Development $\cdot$ Lockdown $\cdot$ COVID-19 $\cdot$ NARDL

\section{Introduction}

Human history is riddled with infectious diseases that left thousands of people dead from the start. Global pandemics have always caused issues to human lives and the global environment. Researchers believe that pandemics' probabilities have been dramatically amplified over the past century, mainly due to greater exploitation of the natural environment,

Amit Kumar

amitkdah@nuist.edu.cn

Extended author information available on the last page of the article 
Biweekly cases per million people, Dec 1, 2020

Biweekly confirmed cases refer to the cumulative number of confirmed cases over the previous two weeks.

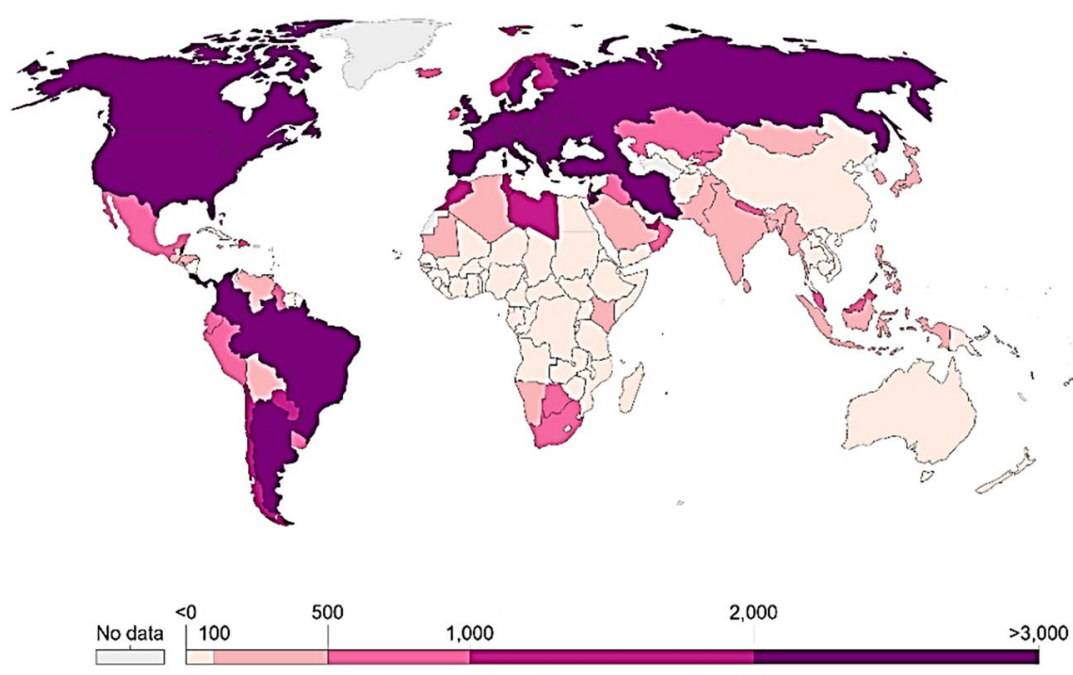

Source: Johns Hopkins University CSSE COVID-19 Data - Last updated 12 January, 06:02 (London time)

$\mathrm{CCBY}$

Fig. 1 Biweekly COVID-19 daily-confirmed cases

urbanization, improved global travel and integration, and land-use changes (Jones, Patel \& Levy, 2008). These trends will keep on getting intensify with each passing day. In the early 2000s, when SARS (severe acute respiratory syndrome) was started spreading worldwide, the World Health Organization (WHO) issued a warning of massive damage to the whole world (Madhav \& Wolfe, 2017).

No doubt, the world has suffered pandemics throughout history, and they keep on appearing with higher frequency each time. The world is currently dealing with another great pandemic of the century that is COVID 19. Coronavirus is a highly contagious virus in Wuhan, China, in December 2019 (Haleem \& Javaid, 2020). From China, it has spread all across the world. Millions of people have lost the battle of their lives against this deadly virus. COVID-19 has rapidly affected our daily life and business activities. It has caused restricted movements and disrupted supply chain activities worldwide. Most businesses face lower or no sales, reducing manufacturing activities. COVID-19 has also greatly influenced the global environment. Figure 1 shows biweekly CPVID-19 cases per million people.

Since the last few decades, the world has experienced a tremendous environmental pollution increase. Despite the enormous efforts, environmental pollution is a significant issue and poses a continuing risk to human lives. In the current global environment, where business activities are increasing, environmental pollution is also going upward at a higher pace. Most researchers believe that environmental pollution is a source of various diseases and affects human health by increasing exposure to different diseases (Kelishadi, 2012). Undoubtedly, this problem is most significant in developing countries. The traditional sources of pollution are still in processes, such as contaminated water supply, inadequate waste management, poor sanitation, and high exposure to indoor air pollution (Kumar, Taxak, et al., 2021). Pollution is directly correlated with the population. According to the 
United Nations (2019), the world population may rise to 11 billion by 2100 , which will cause the environmental population.

Environmental pollution has reached to troublesome amount all over the world. Economic development, industrialization, and urbanization have caused an increase in greenhouse emissions (Kumar \& Sharma, 2017; Kumar, Thanki, et al., 2021; Sharma et al., 2020; Tobías et al., 2020; Wang, Chen, et al., 2020; Wang, Zhang, et al., 2020). Thus, carbon dioxide and other toxic gases are released into the atmosphere polluting the air and increasing its temperature. This has become the reason for the depletion of the ozone layer, which significantly affects the daily lives of the people (Edwards, 2018).

Undoubtedly, the novel coronavirus has caused worldwide disruptions that affected the environment and the climate. A significant decrease in travel activities due to lockdowns has dropped air pollution considerably. According to recent research, China has experienced a $25 \%$ and $50 \%$ decrease in carbon emissions and nitrogen oxides, respectively, since the pandemic (Myllyvirta, 2020). A scientist estimated that it might save at least 77,000 lives over two months. Almost every country has implemented lockdowns to reduce coronavirus spread, which reduced industrial activities and transportation services. This has dramatically brought down the worldwide pollution level. The European Space Agency observed a significant decline in nitrous emissions from factories, power plants, and cars in Northern Italy, mainly due to strict curfew in the region (Green, 2020).

The European Space Agency (ESA) and the National Aeronautics and Space Administration (NASA) have been closely monitoring the ozone layer in the current pandemic. According to them, the decrease in nitrogen oxide started in Wuhan, China, and then slowly spread throughout the world drastically (Zhang \& Zhang, 2020). No doubt, COVID19 has caused havoc to the whole world. However, it is also considered a "Blessing in Disguise," as nature is reclaiming itself. Poor quality is harmful to the entire population. Around 4.6 million people die every year due to poor quality worldwide. Air pollution is a huge problem, and its effects are visible to the developed nations. In 2012, around 193,000 people died in Europe due to air pollution (Brauer \& Burnett, 2017).

\subsection{COVID-19 in India}

Like any other country, India has also experienced a sudden decrease in carbon emission and environmental pollution due to lockdown implementation since March 2020 (Gautam et al., 2020). Delhi, India's capital is considered one of the most polluted megacities of the whole world. A report was issued by the World Health Organization in 2018, in which Delhi ranked high in the list of most polluted cities of the world (United Nations, 2018). Mumbai and Delhi, the megacities, are experiencing PM 2.5 concentrations for the last several years, far above tolerable limits, defined by NAAQS (National Ambient Air Quality Standards). The increased air pollution has become the source of various health issues, including acute asthma, pneumonia, respiratory disorders, etc. (Chakraborty \& Maity, 2020; Rizou et al., 2020; SanJuan-Reyes et al., 2020). In 2017, owing to increased air pollution, the Indian Council of Medical Research (ICMR) has declared a community health emergency in Delhi (Verma \& Prakash, 2020; Lokhandwala \& Gautam, 2020; Wang \& Su, 2020; Amdade et al., 2021; Gautam et al., 2020, 2021). India's bad air quality is a key reason for premature deaths (Dandona \& Shukla, 2017).

To minimize coronavirus spread, the Indian government implemented a nationwide lockdown from March 24 for three weeks, and later, it further extended. The government has also banned all kinds of industrial activities and mass transportations all over the country. 
Resultantly, Sharma et al. (2020) stated pollution level had been significantly decreased in 88 cities of India, only after four days of commencing the lockdown event. The nitrogen oxide level has also dropped to $90 \mu \mathrm{mol} / \mathrm{m}^{2}$ in March 2020 in Delhi, $158 \mu \mathrm{mol} / \mathrm{m}^{2}$ in March 2019. Mumbai further dropped to $77 \mu \mathrm{mol} / \mathrm{m} 2,122 \mu \mathrm{mol} / \mathrm{m}^{2}$ last year (Poetzscher, 2020). The coronavirus has caused disruptions in India, but it has proved a "blessing in disguise" for minimizing the country's environment and air pollution (Eroğlu, 2020; Shakil et al., 2020; Wilder-Smith \& Freedman, 2020). Figure 2 represents daily COVID-19-confirmed cases and deaths in India from January 30, 2020, to February 21, 2021.

The current study aims to analyze the effect of carbon emission on sustainable development during COVID-19. As per the rules and regulations of lockdown, all types of human activities were banned, and India's people were restricted from living in their homes. The daily pausing activities reduce transportation emissions, and the businesses do not contribute to pollution and emission of toxic gases during the lockdown. Purposely, this research analyses the relationship between lockdown and carbon dioxide emission and the nature and direction of relation to its long-run relationship or short-run relationship.

\section{Literature review}

The coronavirus outbreak restricted almost all avoidable activities in China and worldwide since the first call of lockdown in Wuhan on January 23, 2020. The transmission rate of SARS-COVID-2 is comparatively high compared to its predecessors (Bherwani, Anjum, et al., 2020). By employing the Community Multi-Scale Air Quality (CMAQ) model with monthly anthropogenic emission data of China, it is observed that the concentration

\section{Daily confirmed COVID-19 cases and deaths, India \\ The confirmed counts shown here are lower than the total counts. The main reason for this is limited testing and challenges in the attribution of the cause of death.}

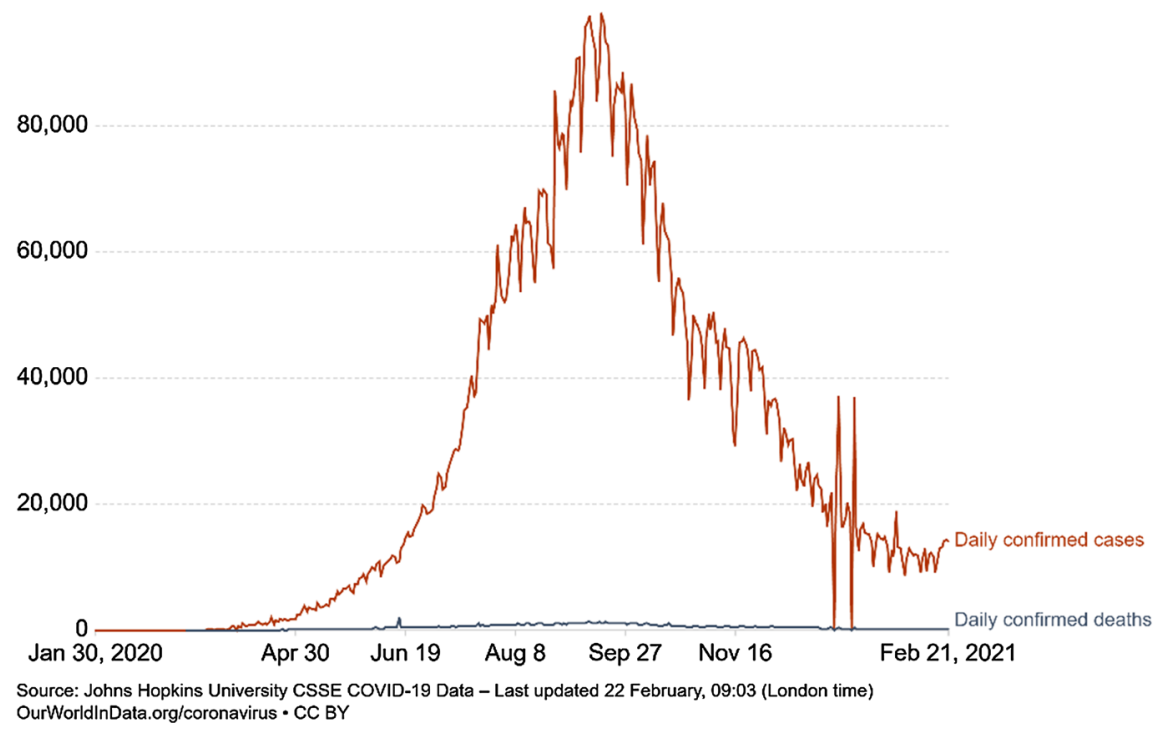

Fig. 2 Daily confirmed cases and deaths in India 
of $\mathrm{PM}_{2.5}$ decreased almost $20 \%$ in Guangzhou, Shanghai, Beijing, Shijiazhuang, Tianjin, Jinan, Taiyuan, Xi' an, Zhengzhou, and Wuhan. It is observed that the meteorology was unfavorable during the simulation episode. The $\mathrm{PM}_{2.5}$ emission's concentration is reduced $\sim 2$ times in lockdown. A large emission reduction is observed in transportation and slight emission reduction in the industrial sector due to working being stopped in the industrial sector. Still, it does not decrease the pollution of China prominently. The pandemic and lockdown are imposed on all countries for a specific time and specific reason, so it is not applicable for reducing pollution. For avoiding severe air pollution, more efforts should be made to complete the task of environmental sustainability (Ambade et al., 2021; Bherwani, Nair, et al., 2020; Srivastava et al., 2020; Wang, Chen, et al., 2020; Wang, Zhang, et al., 2020). To control the rapidly increasing affected cases and death rate, the major strategies in clinical trials, medications, vaccinations, and social distancing for social and individual protection were designed by individual countries and the World Health Organization (WHO) (Gautam \& Hens, 2020).

The morbidity and mortality are being increased due to air pollution, and the rate of it is rapidly increased year by year. Air pollution leads to health risks and environmental degradation by acid rains and reduced visibility. The rise in obstructive pulmonary disease (COPD), cardiovascular disease, and respiratory ailments like asthma and chronic bronchitis are just because of poor air quality management. As we know that the COVID-19 outbreak abruptly stopped all human activities, so in these situations and circumstances, the air pollution showed a significant reduction in it. If the rate of newly affected cases of COVID-19 was increased, the causes of morbidity and mortality with air pollution were decreased. The National Aeronautics and Space Administration (NASA) and European Space Agency (ESA) released the data of healing environmental sustainability during strict lockdown during an outbreak of COVID-19. The reduction rate of pollution in some of the epicenters like Wuhan, Italy, Spain, and the USA has 30\%, which increases the sustainability of the environment and quality of air (Muhammad et al., 2020). Bherwani, Anjum, et al. (2020) monetarily quantified the declining trend in health impact due to air pollution reduction during the lockdown. Utilizing two types of data, i.e., environmental-related data and monetized health impact data from 2019 to 2020 and capturing four cities-Delhi, London, Paris, and Wuhan, analyzed air pollution reduction. Undoubtedly, these four cities suffered from economic damages, but this research noted the comparative preventing air pollution reduction benefits due to lockdown. This research also provides a pathway to compare the magnitude of actual damage environmentally and the damage-related lockdown.

Gautam et al. (2020) used seven environmental pollutants, i.e., $\mathrm{PM}_{2.5}, \mathrm{PM}_{10}, \mathrm{NO}_{2}, \mathrm{NH}_{3}$, $\mathrm{SO}_{2}, \mathrm{CO}_{2}$, and O3, to calculate the Air Quality Index (AQI) from February 17, 2020, to May 4, 2020. In this research, Gautam et al. (2021) measured the variations of air quality of Delhi (DTU, Okhla, and Patparganj), Haryana (Jind, Palwal, and Hisar), and Uttar Pradesh (Agra, Kanpur, and Greater Noida) and data have been retrieved from the Central Pollution Control Board website. The Air Quality Index has upgraded 30-47\% approximately during the lockdown. The air mass contribution and healing layers of $\mathrm{O}_{3}$ have been observed by the air mass back trajectory (AMBT) analysis in India and Europe, Africa, and Gulf countries during the lockdown. Gautam et al. (2021) revised the research by including extra air quality factors and upgraded the research direction's accuracy. This research captured the eight most polluted cities of India, i.e., Mumbai, Delhi, Bangalore, Hyderabad, Lucknow, Chandigarh, Kolkata, and Ahmedabad. The environmental sustainability behavior of these cities is checked during the COVID-19 lockdown. The significant reduction of environmental pollutants over Major Dhyan Chand Stadium has been observed as $\mathrm{PM}_{2.5}(63 \%)$, $\mathrm{PM}_{10}(56 \%), \mathrm{NO}_{2}(50 \%), \mathrm{SO}_{2}(9 \%)$, and $\mathrm{CO}(59 \%)$. In comparison, the $\mathrm{PM}_{2.5}(44 \%), \mathrm{PM}_{10}$ 
(50\%) decreased over Chhatrapati Shivaji International Airport in India's initial few weeks of strict lockdown.

The overall Air Quality Index (AQI) of Chandigarh and Ballygunge was dramatically upgraded from 7 to $67 \%$. Divergent places of India's major cities were observed, and individual cities of crowded places showed the same results. Long-range transportation has occupied a large portion of toxic emissions. During the lockdown, the trade activities between Iran, Afghanistan, Saudi Arabia, Indian Gangetic plains, and Delhi Non-capital region were stopped. The results of the Hybrid Single-Particle Lagrangian Integrated Trajectory (HYSPLIT) analysis also confirmed the up-gradation of environmental quality during the lockdown. Bherwani, Nair, et al. (2020) analyzed India's data, especially the states of Maharashtra, Gujarat, Madhya Pradesh, Rajasthan, Tamil Nadu, West Bengal, Uttar Pradesh, and Delhi as a union territory on lockdown and social distancing policies by employing Bayesian probability model (BPM). The accuracy and positive resulting of lockdown were analyzed using the change point analysis (CPA), which confirmed the diminishing trend in newly reported cases and the death rate of COVID19 patients. The delta values are between 9.6 and 4.7 for Gujarat and Madhya Pradesh and Maharashtra, respectively, At the same time, all states showed a strong significant correlation $(p<0.05, t-$ stat $>t-$ critical $)$ toward a different period of CPA and lockdown (cases per population (CPP) and cases per unit area (CPUA)). The weak correlation $(p<0.1, t-$ stat $<t-$ critical $)$ is observed by delta and cases per unit population density (CPD). Although the correlation is significant for CPP and CPUA, Pearson's correlation confirmed a negative direction.

\section{Methodology}

\subsection{Data description}

The daily data of deaths, covid-19-confirmed cases, and lockdown are utilized to analyze the impact of COVID-19 on $\mathrm{CO}_{2}$ emission. This research comprises data from January 31, 2020, to December 1, 2020. The data series is divided into three parts: pre-lockdown, during the lockdown, and post-lockdown (Mohsin, Naiwen, et al., 2020; Mohsin, Naseem, et al., 2020). In India, the first confirmed COVID-19 case was reported on January 30, 2020. Under India's pandemic government, the global and domestic adverse spreading situation announced a strict lockdown on March 25, 2020, and it was prolonged till May 31, 2020. The visual presentation of $\mathrm{CO}_{2}$ emission data from January 30, 2020, to December 1, 2020, can be seen in Fig. 1. The daily data of confirmed cases and deaths are extracted from the World Health Organization (WHO). In contrast, the daily data of $\mathrm{CO}_{2}$ emission in India are obtained from carbon monitor (Asadi et al., 2020; Chakraborty \& Ghosh, 2020; Guo et al., 2020).

The analysis is performed on the below-mentioned model:

$$
\ln \mathrm{CO}_{2 t}=f\left(\mathrm{NC}_{t}^{+}, \mathrm{NC}_{t}^{-}, \mathrm{ND}_{t}^{+}, \mathrm{ND}_{t}^{-}, \mathrm{LD}_{t}^{+}, \mathrm{LD}_{t}^{-}\right)
$$

The partial sum of positive and negative shocks in NC, ND, and LD is determined by employing the nonlinear autoregressive distributed lag (NARDL) method. Before exploring the primary model, the divergent test's data series have been checked for suitability of the NARDL method. The unsuitable data set can be misled due to fundamental analysis (Ouattara, 2004). 


\subsection{Unit root test}

Unit root test is used to check the stationarity of data series. The augmented Dickey-Fuller (ADF) and Phillips-Perron (PP) tests are employed to inspect the unit root.

$$
\begin{gathered}
\Delta Y_{t}=\alpha+\beta_{t}+\rho Y_{t-1}+\sum_{i=1}^{k} \gamma_{i} \Delta Y_{t}+e_{t} \\
\Delta Y_{t}=(p-1) Y_{t-1}+e_{t}
\end{gathered}
$$

The equation-2 is ADF, and equation-2 PP test equation for unit root to check the data series's stationarity. These equations $\Delta$ represent the first difference operator, and $Y_{t}$ shows a high order of autocorrelation concerning time. The endogenous variables are presented as $Y_{t-1}$. The $e_{t}$ is the error term in both tests of equation-2 and equation-3 (Fig. 3).

\subsection{Standard nonlinear autoregressive distributed lag (NARDL) model}

The nonlinear autoregressive distributed lag (NARDL) model is introduced by Shin et al. (2014). The standard ARDL model is restricted to check the linear relationship between independent and dependent variables, while some are nonlinearly related (Hu et al., 2018; Shahzad et al., 2017). The nonlinear ARDL model is covered with negative and positive changes of variables. The $\boldsymbol{x}_{\boldsymbol{t}}$ in the following equation of the NARDL model shows the decomposition into a partial sum of positive and negative changes as:

$$
\begin{gathered}
x_{t}=x_{0}+x_{t}^{+}+x_{t}^{-} \\
\text {where } x_{t}^{+}=\sum_{i=1}^{t} \Delta x_{i}^{+}=\sum_{i=1}^{t} \max \left(\Delta x_{i}, 0\right) \\
x_{t}^{-}=\sum_{i=1}^{t} \Delta x_{i}^{-}=\sum_{i=1}^{t} \min \left(\Delta x_{i}, 0\right)
\end{gathered}
$$

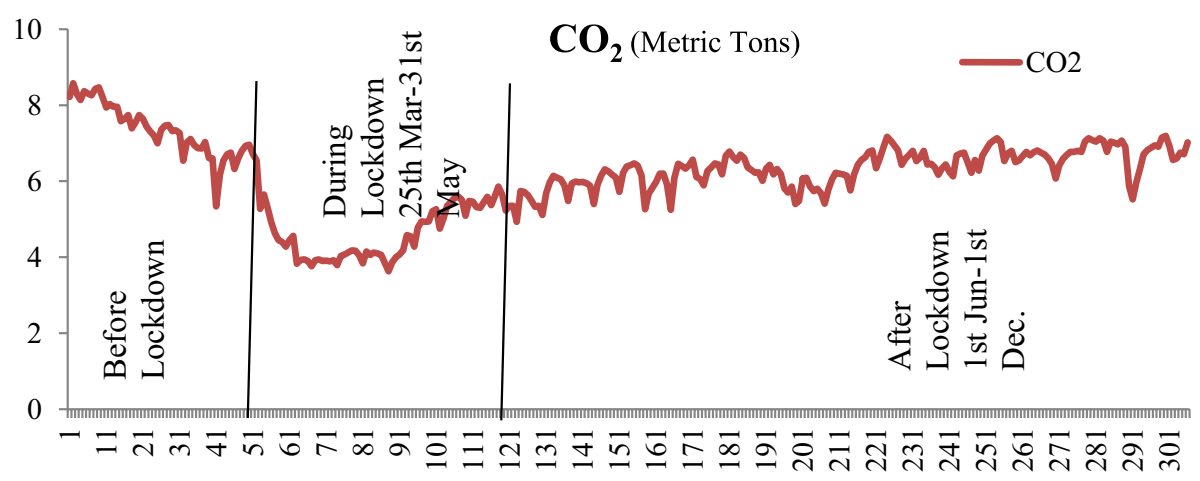

Fig. $3 \mathrm{CO}_{2}$ emission in India during pandemic (COVID-19) 
The following equation can be used to examine the asymmetric long-run equilibrium relationship:

$$
y_{t}=\beta^{+} x_{t}^{+}+\beta^{-} x_{t}^{-}+\mu_{t}
$$

In equation-3, the parameter $\boldsymbol{\beta}^{+}$and $\boldsymbol{\beta}^{-}$are asymmetric long-run parameters which accordingly related to positive and negative variations in $\boldsymbol{x}_{\boldsymbol{t}}$. The combination of equation-4 and equation-5 with the ARDL model generates the following NARDL model:

$$
\Delta y_{t}=\beta_{0}+\beta_{1 i} \sum_{i=1}^{t} \Delta y_{t-i}+\beta_{n, i} \sum_{i=1}^{t}\left(+\Delta x_{t-i}^{+}+\ldots \Delta x_{t-i}^{-}\right)+\vartheta_{1} y_{t-i}+\vartheta_{n, i} x_{t-1}^{+}+\vartheta_{n, i} x_{t-1}^{-}+\mu_{t}
$$

The equation-6 consists of two parts: the short-run asymmetry is tested by $\beta_{n, i} \sum_{i=1}^{t} \Delta x_{t-i}^{+}, \beta_{n, i} \sum_{i=1}^{t} \Delta x_{t-i}^{-}$while the long-run asymmetry determined by $\beta^{+}=\beta^{-}$(i.e., $\left.-\vartheta / \beta^{+}=-\vartheta / \beta^{-}\right)$.

The nonlinear ARDL model is formulated for this study as:

$$
\begin{aligned}
& \Delta \ln \mathrm{CO}_{2 t}= \beta_{0} \\
&+\beta_{1 i} \sum_{i=1}^{t} \Delta \ln \mathrm{CO}_{2 t-i}+\beta_{2 a} \sum_{i=1}^{t} \Delta \ln \mathrm{NC}_{t-i}^{+}+\beta_{2 b} \sum_{i=1}^{t} \Delta \ln \mathrm{NC}_{t-i}^{-}+\beta_{3 a} \sum_{i=1}^{t} \Delta \ln \mathrm{ND}_{t-i}^{+} \\
&+\beta_{3 b} \sum_{i=1}^{t} \Delta \ln \mathrm{ND}_{t-i}^{-}+\beta_{4 a} \sum_{i=1}^{t} \Delta \ln \mathrm{LD}_{t-i}^{+}+\beta_{4 b} \sum_{i=0}^{t} \Delta \ln \mathrm{LD}_{t-i}^{-}+\vartheta_{1} \ln \mathrm{CO}_{2 t-i}+\vartheta_{2 a} \Delta \ln \mathrm{NC}_{t-1}^{+} \\
&+\vartheta_{2 b} \Delta \ln \mathrm{NC}_{t-1}^{-}+\vartheta_{3 a} \Delta \ln \mathrm{ND}_{t-1}^{+}+\vartheta_{3 b} \Delta \ln \mathrm{ND}_{t-1}^{-}+\vartheta_{4 a} \Delta \ln \mathrm{LD}_{t-1}^{+}+\vartheta_{4 b} \Delta \ln \mathrm{LD}_{t-1}^{-} \\
&+\mu_{t}
\end{aligned}
$$

where $\mathrm{CO}_{2 t}$ represents the $\mathrm{CO}_{2}$ emission of India in the COVID-19 era at time $t$, the partial sum of positive and negative changes in new confirmed cases of COVID-19 represented by $N C_{t-i}^{+}$and $N C_{t-i}^{-}$, respectively, at time $t$. The newly confirmed death is shown as $N D_{t-i}^{+}$ and $N D_{t-i}^{-}$, and the positive partial sum and negative partial sum of lockdown are presented as $L D_{t-i}^{+}$and $L D_{t-i}^{-}$with time $t$. The lockdown is used as a dummy variable in this analysis (Barati \& Fariditavana, 2020; Bahmani-Oskooee \& Saha, 2017). The dummy variable is justified in assigning the binary number; 1 is assigned to the lockdown period and 0 for the unlocked period. The error term is presented as $\mu_{t}$. The NARDL model can only be employed in variables integration at the order I(0) or I(1). The NARDL model is not suitable if the variables are integrated into two I(2) (Greenwood-Nimmo \& Shin, 2013; Shin et al., 2014). Using the ADF and PP test, the PP test applies a nonparametric correction to the standard ADF test statistics. More general dependence in error and conditional heteroskedasticity is also checked. Both tests are used to check the stationarity of the series.

\section{Results and discussion}

The summary statistics of $\mathrm{CO}_{2}$ emission, newly confirmed cases, and newly confirmed deaths are presented in Table 1. The mean of $\mathrm{CO}_{2}$ emission (6.127) is lower than $\mathrm{NC}$ $(30,924.210)$ and ND (449.745). The maximum and minimum values of variables present a clear picture of the relationship between $\mathrm{CO}_{2}$ emission and COVID-19. The maximum value of the $\mathrm{CO}_{2}$ emission is 8.580 , and the minimum value is 3.630 . The 4.950 
Table 1 Descriptive statistics

\begin{tabular}{llll}
\hline & $\mathrm{CO}_{2}$ & $\mathrm{NC}$ & $\mathrm{ND}$ \\
\hline Mean & 6.127 & $30,924.210$ & 449.745 \\
Median & 6.320 & $19,682.500$ & 438.500 \\
Maximum & 8.580 & $97,894.000$ & 2003.000 \\
Minimum & 3.630 & 0.000 & 0.000 \\
Std. Dev & 1.057 & $30,921.330$ & 405.705 \\
Skewness & -0.465 & 0.556 & 0.513 \\
Kurtosis & 2.996 & 1.929 & 2.328 \\
Jarque-Bera & $11.041^{*}$ & $30.416^{*}$ & $19.182^{*}$ \\
Probability & 0.004 & 0.000 & 0.000 \\
Observations & 306 & 306 & 306 \\
\hline
\end{tabular}

$*$, **, and $* * *$ represent $1 \%, 5 \%$, and $10 \%$ level of significance, respectively

metric tones reduction in $\mathrm{CO}_{2}$ emission is observed in India during COVID-19, while an increasing trend is observed in new confirmed cases and newly confirmed deaths. The drastic increase in the standard deviation of NC (30,921.330) and ND (405.705) is shown. The value of standard deviation variation of $\mathrm{CO}_{2}$ emission is 1.057 . The latest confirmed cases and newly confirmed deaths show positive skewness, while $\mathrm{CO}_{2}$ emission is negatively skewed. The kurtosis value of all variables is significant at a $1 \%$ level of significance, and more than three, which means data are not normally distributed (Mohsin, Naiwen, et al., 2020; Mohsin, Naseem, et al., 2020; González et al., 2020; Shehzad et al., 2020; Hashmi et al., 2020).

The data series's stationarity is checked by performing two unit root tests, i.e., the augmented Dickey-Fuller (ADF) and Phillips-Perron (PP) test. The unit root test results are presented in Table 2, which shows that all variables are stationary at first difference. There are two terms to show cointegration I(0) for non-stationary series and I(1) for stationary data series. The data series's stationarity confirms the data fit for the cointegration process in the NARDL framework.

Table 2 Unit root test

\begin{tabular}{|c|c|c|c|c|c|}
\hline \multirow[t]{2}{*}{ Variables } & \multicolumn{2}{|l|}{$\mathrm{ADF}$} & \multicolumn{2}{|l|}{$\mathrm{PP}$} & \multirow{2}{*}{$\begin{array}{l}\text { Order of } \\
\text { cointegra- } \\
\text { tion }\end{array}$} \\
\hline & Level & First difference & Level & First difference & \\
\hline \multirow[t]{2}{*}{$\mathrm{CO} 2$} & -2.28218 & $-9.979 *$ & -2.434 & $-19.523^{*}$ & \multirow[t]{2}{*}{$\mathrm{I}(1)$} \\
\hline & 0.1785 & 0.000 & 0.133 & 0.000 & \\
\hline \multirow[t]{2}{*}{$\mathrm{NC}$} & -1.02597 & $-14.215^{*}$ & -1.366 & $-19.177 *$ & \multirow[t]{2}{*}{$\mathrm{I}(1)$} \\
\hline & 0.7447 & 0.000 & 0.599 & 0.000 & \\
\hline \multirow[t]{2}{*}{ ND } & -1.31653 & $-13.303 *$ & -2.554 & $-49.982 *$ & \multirow[t]{2}{*}{$\mathrm{I}(1)$} \\
\hline & 0.6226 & 0.000 & 0.104 & 0.000 & \\
\hline \multirow[t]{2}{*}{ LD } & -1.71519 & $-7.668 *$ & -1.724 & $-17.378^{*}$ & \multirow[t]{2}{*}{$\mathrm{I}(1)$} \\
\hline & 0.4226 & 0.000 & 0.418 & 0.000 & \\
\hline
\end{tabular}

$*$, **, and $* * *$ represent $1 \%, 5 \%$, and $10 \%$ level of significance, respectively 
Table 3 The result of bound tests for cointegration test

\begin{tabular}{|c|c|c|c|c|c|c|c|c|}
\hline \multirow[b]{2}{*}{ F-statistics } & \multicolumn{2}{|l|}{$10 \%$} & \multicolumn{2}{|l|}{$5 \%$} & \multicolumn{2}{|c|}{$2.50 \%$} & \multicolumn{2}{|l|}{$1 \%$} \\
\hline & $\mathrm{I}(0)$ & $\mathrm{I}(1)$ & $\mathrm{I}(0)$ & $\mathrm{I}(1)$ & $\mathrm{I}(0)$ & $\mathrm{I}(1)$ & $\mathrm{I}(0)$ & $\mathrm{I}(1)$ \\
\hline 993 & 1.99 & 2.94 & 2.27 & 3.28 & 2.55 & 3.61 & 2.88 & 3.99 \\
\hline
\end{tabular}

Akaike Information Criteria (top 20 models)

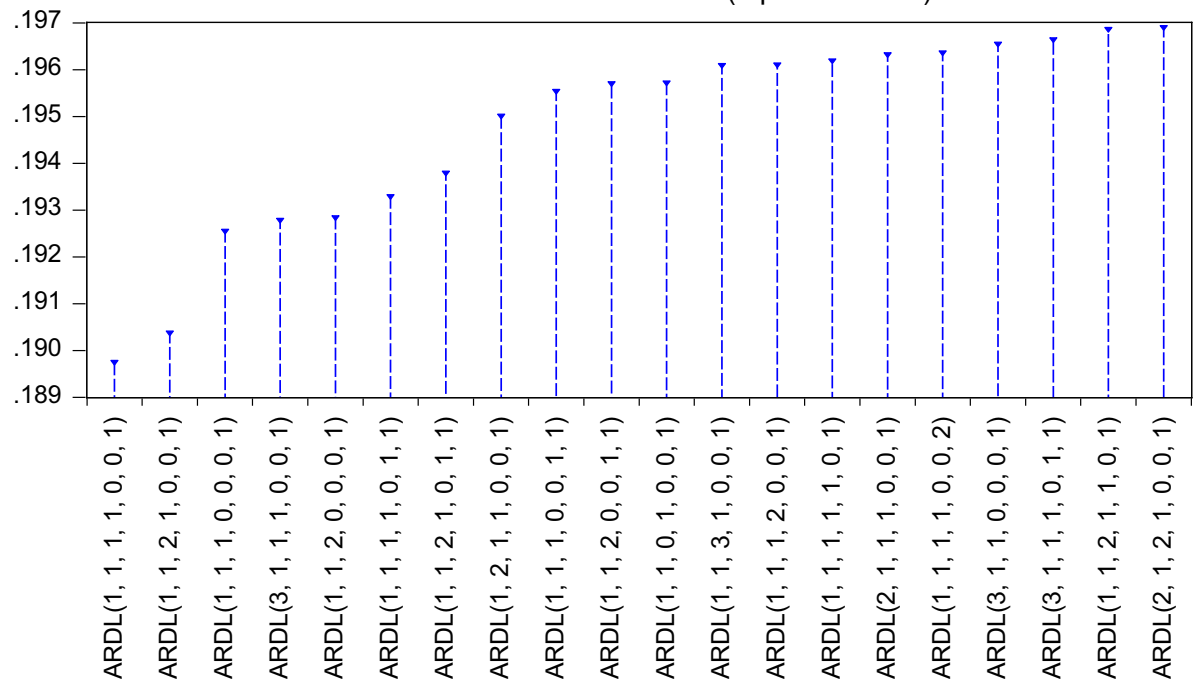

Fig. 4 AIC top 20 models

The results of the bound test for cointegration are displayed in Table 3. The F-statistics value (3.993) is larger than the upper critical value (3.99) at a $1 \%$ level of significance. The automatic lag specification of the NARDL model is $1,1,1,1,0,0$, 1, which is selected based on the Akaike information criterion (AIC) (Mohsin, Naiwen, et al., 2020; Mohsin, Naseem, et al., 2020; Zhang et al., 2017; Shah et al., 2020). The model specification with AIC-based lag length is presented in Fig. 4. It vehemently rejects the null hypothesis of no cointegration (F-statistics < lower bound critical value). F-statistics significance at a $1 \%$ level confirms the cointegration occurrence for a long-run relationship between $\mathrm{CO}_{2}$ emission and COVID-19 with its determinants (Katrakilidis \& Trachanas, 2012; Sarfraz et al., 2018, 2020; Zhang et al., 2017).

After confirming the long-run cointegration relationship between $\mathrm{CO}_{2}$ emission and COVID-19 (new confirmed cases, new confirmed deaths, and lockdown), the next step particularly determined the long-run or short-run asymmetry from the primary model (7). The long-run dynamic asymmetry estimation results are presented in Table 4 . The long-run coefficient of $\mathrm{CO}_{2}$ emission (0.87225) is positively significant at a $1 \%$ level of significance. As per the results, we can say that a $1 \%$ increase in COVID-19 with its determinants becomes the reason for an $87.225 \%$ decrease in $\mathrm{CO}_{2}$ emission. The $\mathrm{NC}^{+}$ $(-1), \mathrm{NC}^{-}, \mathrm{LD}^{+}, \mathrm{LD}^{-}$, and $\mathrm{LD}^{-}(-1)$ are significant at $1 \%$ level, while $\mathrm{NC}^{+}$and $\mathrm{ND}^{-}$ are significant at $10 \%$ and $5 \%$ level of significance. The $\mathrm{NC}^{-}(-1), \mathrm{ND}^{+}$, and $\mathrm{ND}^{+}(-1)$ demonstrate the positivity with insignificance. 
Table 4 Dynamic asymmetric estimation of $\mathrm{CO}_{2}$ emission

\begin{tabular}{lccrl}
\hline Variable & Coefficient & Std. Error & t-Statistic & \multicolumn{1}{l}{ Prob } \\
\hline $\mathrm{CO} 2(-1)$ & $0.87225^{*}$ & 0.02977 & 29.29808 & 0.00000 \\
$\mathrm{NC}^{+}$ & $0.00001 * * *$ & 0.00001 & 1.83384 & 0.06770 \\
$\mathrm{NC}^{+}(-1)$ & $-0.00002 *$ & 0.00001 & -3.14186 & 0.00190 \\
$\mathrm{NC}^{-}$ & $-0.00002 *$ & 0.00001 & -2.99747 & 0.00300 \\
$\mathrm{NC}^{-}(-1)$ & 0.00001 & 0.00001 & 1.94004 & 0.05330 \\
$\mathrm{ND}^{+}$ & 0.00011 & 0.00015 & 0.72058 & 0.47170 \\
$\mathrm{ND}^{+}(-1)$ & 0.00061 & 0.00037 & 1.64726 & 0.10060 \\
$\mathrm{ND}^{-}$ & $0.00070 * *$ & 0.00034 & 2.03899 & 0.04240 \\
$\mathrm{LD}^{+}$ & $-0.31990 *$ & 0.09516 & -3.36185 & 0.00090 \\
$\mathrm{LD}^{-}$ & $-0.79436 *$ & 0.26400 & -3.00894 & 0.00290 \\
$\mathrm{LD}^{-}(-1)$ & $0.75017 *$ & 0.27074 & 2.77077 & 0.00600 \\
$\mathrm{C}^{-}$ & $0.86460 *$ & 0.21884 & 3.95087 & 0.00010 \\
\hline
\end{tabular}

$*$, **, and $* * *$ represent $1 \%, 5 \%$, and $10 \%$ level of significance, respectively

The asymmetrically short- and long-run results are displayed in Tables 5 and 6. The recent confirmed case is significant at 5\% with a positive sign and the negative new confirmed cases also significant at a $1 \%$ level. The new confirmed death positive is displayed in a table, which is positively insignificant. The lockdown coefficient shows negative significance at a $1 \%$ level for the short run. The ECT term confirms the long-run relationship between $\mathrm{CO}_{2}$ emission and COVID-19 with its determinants with its significance at $1 \%$ and the negative sign's assumption. The second half of Table 5 presents long-run asymmetric coefficients with their confirmation of significance or

Table 5 Result of asymmetric short run

\begin{tabular}{lllrl}
\hline Variable & Coefficient & Std. error & t-Statistic & \multicolumn{1}{l}{ Prob } \\
\hline $\mathrm{D}\left(\mathbf{N C}^{+}\right)$ & $1.19 \mathrm{E}-05^{* *}$ & $5.14 \mathrm{E}-06$ & 2.3208 & 0.0210 \\
$\mathrm{D}\left(\mathbf{N C}^{-}\right)$ & $-2.36 \mathrm{E}-05^{*}$ & $5.98 \mathrm{E}-06$ & -3.9457 & 0.0001 \\
$\mathrm{D}\left(\mathbf{N D}^{+}\right)$ & 0.0001 & 0.0001 & 0.7603 & 0.4477 \\
$\mathrm{D}\left(\mathbf{L D}^{-}\right)$ & $-0.7944^{*}$ & 0.2577 & -3.0824 & 0.0022 \\
$\mathrm{ECT}_{\mathrm{t}-1}$ & $-0.1278^{*}$ & 0.0223 & -5.7190 & 0.0000 \\
\hline
\end{tabular}

Table 6 Result of asymmetric long-run coefficients

\begin{tabular}{lllll}
\hline Variable & Coefficient & Std. Error & t-Statistic & Prob \\
\hline $\mathbf{N C}^{+}$ & $-7.06 \mathrm{E}-05^{* *}$ & $3.41 \mathrm{E}-05$ & -2.0711 & 0.0392 \\
$\mathbf{N C}^{-}$ & $-7.42 \mathrm{E}-05^{* *}$ & $3.56 \mathrm{E}-05$ & -2.0842 & 0.0380 \\
$\mathbf{N D}^{+}$ & $0.0056^{* * *}$ & 0.0029 & 1.9576 & 0.0512 \\
$\mathbf{N D}^{-}$ & $0.0055^{* * *}$ & 0.0029 & 1.8932 & 0.0593 \\
$\mathbf{L D}^{+}$ & $-2.5040^{*}$ & 0.3937 & -6.3594 & 0.0000 \\
$\mathbf{L D}^{-}$ & -0.3459 & 0.7250 & -0.4771 & 0.6337 \\
$\mathbf{C}$ & $6.7677^{*}$ & 0.3021 & 22.3990 & 0.0000 \\
\hline
\end{tabular}

$*$, **, and $* * *$ represent $1 \%, 5 \%$, and $10 \%$ level of significance, respectively 
insignificance. The $\mathrm{NC}^{+}$and $\mathrm{NC}^{-}$are significant at a $5 \%$ level of significance, while $\mathrm{ND}+$ and ND are significant at a $10 \%$ level of significance. The $\mathrm{LD}^{+}$is significant at the $1 \%$ level, and $\mathrm{LD}^{-}$is insignificant. The significance of $\mathrm{LD}^{+}$at $1 \%$ with value -2.5040 is explained by the nonlinear relationship between $\mathrm{CO}_{2}$ emission and lockdown. The $\mathrm{CO}_{2}$ emission decreases due to strict lockdown in India during pandemic spread (Azam et al., 2020; Mohsin, Naiwen, et al., 2020; Mohsin, Naseem, et al., 2020; Omoke et al., 2020). As per the graphical presentation, the $\mathrm{CO}_{2}$ emission started decreasing from the starting point of COVID-19 breakout because people stayed in their homes to avoid the risk of viruses. A rapid decrease in $\mathrm{CO}_{2}$ emission is observed after strict lockdown. All types of business and the flow of transport were stopped in strict lockdown, which becomes the reason for $\mathrm{CO}_{2}$ emission reduction in India. This research has covered three phases: pre-lockdown, during-lockdown, and post-lockdown. The adjusted assessment of asymmetry in the presented long-run equilibrium with positive and negative shocks is displayed in a dynamic multiplier graph (Figs. 5, 6, 7). The negative and positive $\mathrm{CO}_{2}$ emission shocks generate a linear mixture of dynamic multiplier asymmetric curves.

Table 7 contains the results of diagnostic tests. The value of Breusch-Godfrey is 1.301, which confirms the model is free from serial correlation. The insignificance of Jarque-Bera with 1.524, ARCH test with 1.734, and Ramsey RESET test with F-statistics value of 0.511 confirmed the normality, absence of heteroskedasticity, and correct specification of the model, respectively. The CUSUM and CUSUM square test shows the stability of the model. The CUSUM and CUSUM ${ }^{2}$ are visually presented in Figs. 8, 9 , which shows the cumulative sum of recursive residuals and its square lies between critical bound 5\% level of significance. The employed model is stable and trustworthy to determined short- and long-run relationship coefficients (Van \& Bao, 2019).

\section{Conclusion}

Every field of life has been adversely shaken by spreading pandemic COVID-19, but it left some positive effect on environmental sustainability. The holes of ozone layers were healing in this pandemic era because of lockdowns worldwide. People were stuck in their homes and all types of businesses and transportations were closed, which

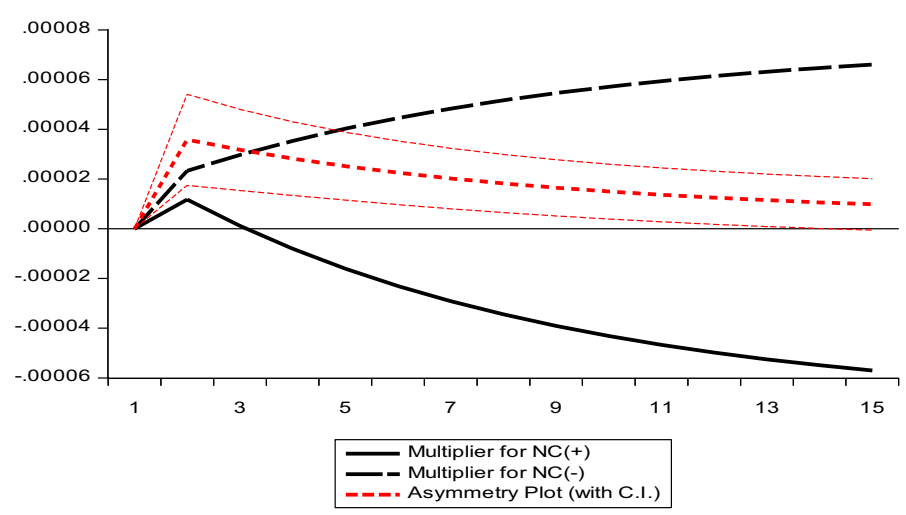

Fig. $5 \mathrm{CO}_{2}$ and $\mathrm{NC}$ dynamic multiplier 


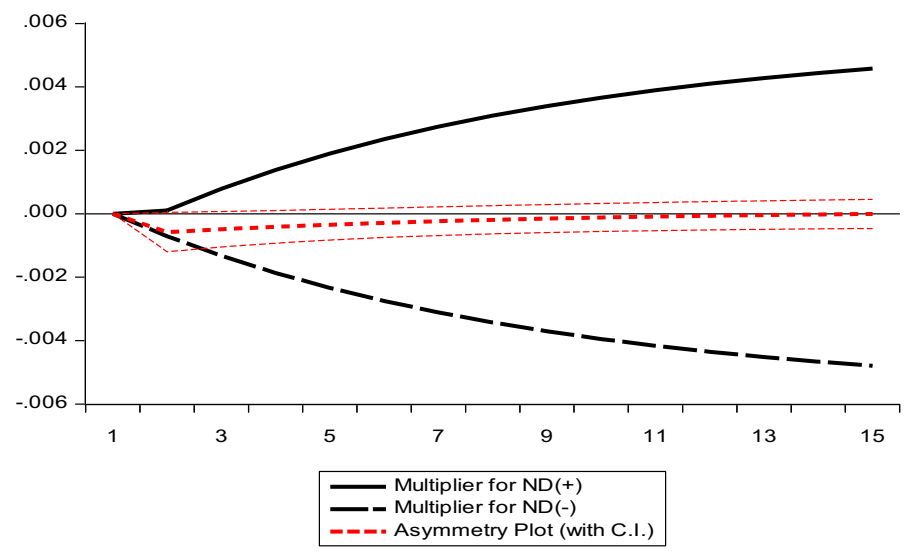

Fig. $6 \mathrm{CO}_{2}$ and ND dynamic multiplier

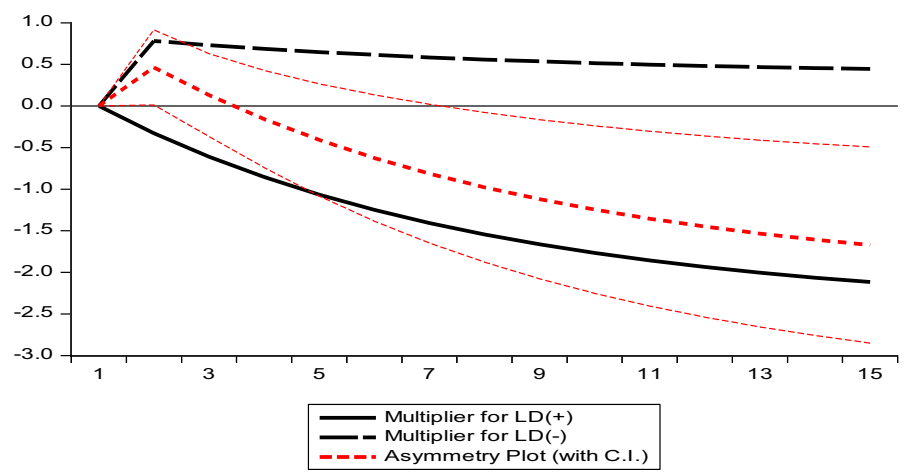

Fig. $7 \mathrm{CO}_{2}$ and LD dynamic multiplier

reduced the emission of toxic gases in the air. This research focused on the relationship between $\mathrm{CO}_{2}$ emission and COVID-19 with its determinants. The asymmetric relationship among $\mathrm{CO}_{2}$ emission, newly confirmed cases, newly confirmed deaths, and lockdown in the COVID-19 era is observed by utilizing daily data from January 30, 2020, to December 1, 2020, for India. The nonlinear autoregressive distributed lag (NARDL) or asymmetric ARDL model is employed to check the long- and short-run relationship between variables. This model's constructive contribution is to simultaneously capture both short- and long-run relationships of variables with negative and positive nature of the relationship. The results of this research confirm the long-run relationship between $\mathrm{CO}_{2}$ emission and COVID-19 in India.

The $\mathrm{CO}_{2}$ emission is negatively influenced by strict lockdown in India. In India, the pandemic starts spreading on January 30, 2020. At the start of COVID-19 spreading, people individually took care to avoid the risk of being infected. Later on, the rapid increase in confirmed cases of COVID-19 patients and increasing death toll compel India's government for strict lockdown. On March 25, 2020, government of India announced a strict lockdown, which extended until May 31, 2020. From January 30, 2020 to March 


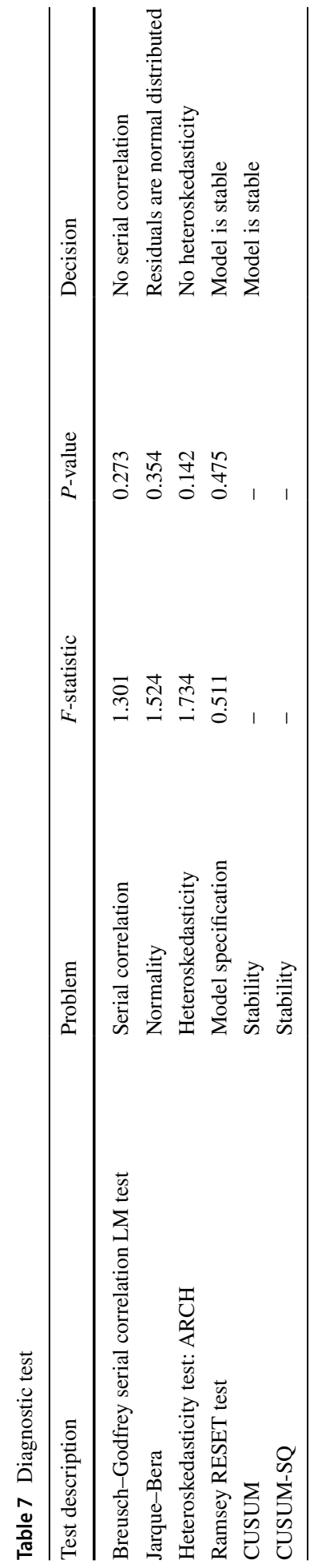




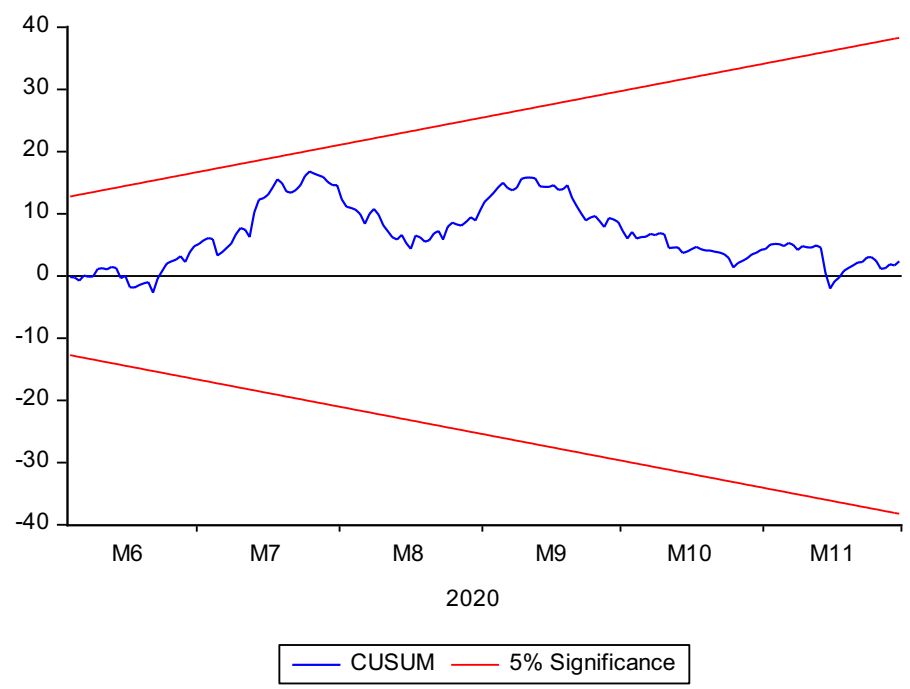

(1): CUSUM for $\mathrm{CO}_{2}$ Emission

Fig. 8 CUSUM for $\mathrm{CO}_{2}$ emission

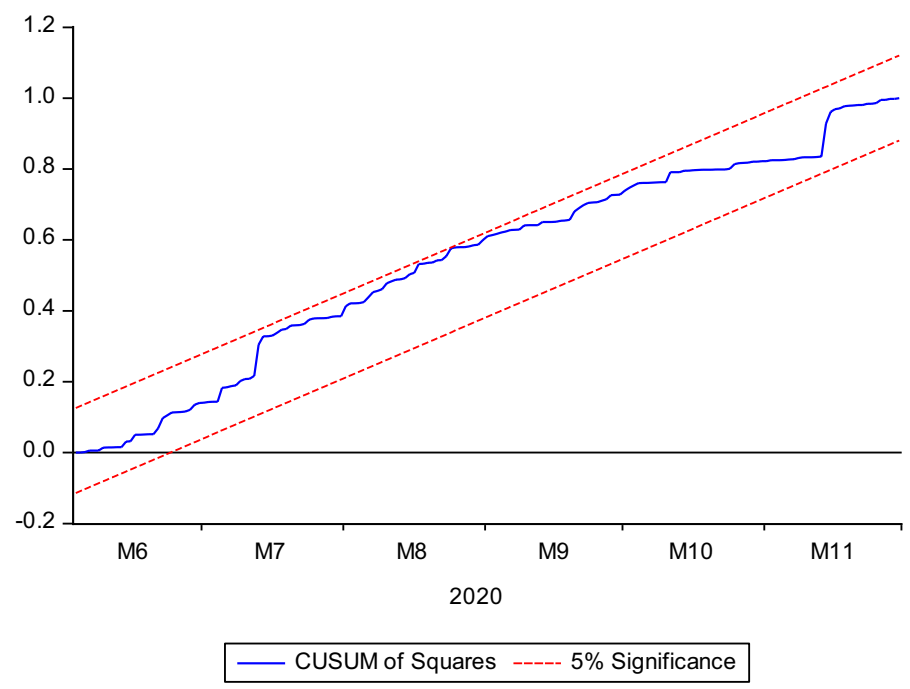

(2): $\mathrm{CUSUM}^{2}$ for $\mathrm{CO}_{2}$ Emission

Fig. 9 CUSUM ${ }^{2}$ for $\mathrm{CO}_{2}$ emission

25, 2020, a minor decrease in $\mathrm{CO}_{2}$ emission has been observed, but a sudden downward trend with a high rate observed after one day of strict lockdown in India. The unlocked situation again contributed to India's $\mathrm{CO}_{2}$ emission, but it is still below the starting value 
(30 January 2020) of $\mathrm{CO}_{2}$ emission. This research suggested that government, policymakers, and businesses reduce the toxic emission of gases for a sustainable environment. No doubt, the lockdown became the cause of $\mathrm{CO}_{2}$ emission reduction in India's environment, but a short-period strategy under special circumstances. This lockdown declared one thing that the human activities and industrial activities in India are unhealthy and environmental unfriendly. The government of India, policymakers, and environmentalists should make the people know about environmentally friendly activities and restricted industries in the sense of toxic gas emissions to enhance environmental purity and prolong its sustainability.

\section{References}

Ambade, B., Sankar, T. K., Kumar, A., et al. (2021). COVID-19 lockdowns reduce the Black carbon and polycyclic aromatic hydrocarbons of the Asian atmosphere: source apportionment and health hazard evaluation. Environment, Development and Sustainability. https://doi.org/10.1007/ s10668-020-01167-1

Asadi, S., Bouvier, N., Wexler, A. S., \& Ristenpart, W. D. (2020). The coronavirus pandemic and aerosols: Does COVID-19 transmit via expiratory particles? Aerosol Science and Technology. https://doi.org/10. 1080/02786826.2020.1749229

Azam, T., Mohsin, M., Naseem, S., Nilofar, M., Zia-UR-Rehman, M., Nelofer, S., \& SongJiang, W. (2020). Economic growth vulnerability amid the COVID-19 epidemic: A systematic review of different sectors of Pakistan. Revista Argentina de Clínica Psicológica, 29(4), 705-713.

Bahmani-Oskooee, M., \& Saha, S. (2017). Nonlinear autoregressive distributed lag approach and bilateral J-curve: India versus her trading partners. Contemporary Economic Policy, 35(3), 472-483. https://doi. org/10.1111/coep.12197

Barati, M., \& Fariditavana, H. (2020). Asymmetric effect of income on the US healthcare expenditure: Evidence from the nonlinear autoregressive distributed lag (ARDL) approach. Empirical Economics, 58(4), 1979-2008. https://doi.org/10.1007/s00181-018-1604-7

Bherwani, H., Anjum, S., Kumar, S., Gautam, S., Gupta, A., Kumbhare, H., \& Kumar, R. (2020). Understanding COVID-19 transmission through Bayesian probabilistic modeling and GIS-based Voronoi approach: A policy perspective. Environment, Development and Sustainability. https://doi.org/10. 1007/s10668-020-00849-0

Bherwani, H., Nair, M., Musugu, K., Gautam, S., Gupta, A., Kapley, A., \& Kumar, R. (2020). Valuation of air pollution externalities: Comparative assessment of economic damage and emission reduction under COVID-19 lockdown. Air Quality, Atmosphere \& Health, 13(6), 683-694. https://doi.org/10. 1007/s11869-020-00845-3

Brauer, M., \& Burnett, R. (2017). Estimates and 25-year trends of the global burden of disease attributable to ambient air pollution: An analysis of data from the global burden of diseases study 2015. The Lancet, 389(10082), 1907-1918.

Chakraborty, I., \& Maity, P. (2020). COVID-19 outbreak: Migration, effects on society, global environment and prevention. Science of the Total Environment. https://doi.org/10.1016/j.scitotenv.2020.138882

Chakraborty, T., \& Ghosh, I. (2020). Real-time forecasts and risk assessment of novel coronavirus (COVID19) cases: A data-driven analysis. Chaos, Solitons \& Fractals, 135, 109850. https://doi.org/10.1016/j. chaos.2020.109850

Dandona, L., \& Shukla, D. (2017). India state-level disease burden initiative collaborators, 2017. Nations within a nation: Variations in epidemiological transition across the states of India 1990-2016 in the global burden of disease study. Lancet, 390(10111), 2437-2460.

Edwards, C. (2018, 12, 11). Future Effects of Pollution. Retrieved from Sciencing: https://sciencing.com/ future-effects-of-pollution-5690014.html

Eroğlu, H. (2020). Effects of Covid-19 outbreak on environment and renewable energy sector. Environment, Development and Sustainability. https://doi.org/10.1007/s10668-020-00837-4

Gautam, A. S., Dilwaliya, N. K., Srivastava, A., Kumar, S., Bauddh, K., Siingh, D., \& Gautam, S. (2020). Temporary reduction in air pollution due to anthropogenic activity switch-off during COVID-19 lockdown in northern parts of India. Environment, Development and Sustainability. https://doi.org/10. 1007/s 10668-020-00994-6 
Gautam, A. S., Kumar, S., Gautam, S., Anand, A., Kumar, R., Joshi, A., \& Singh, K. (2021). Pandemic induced lockdown as a boon to the Environment: Trends in air pollution concentration across India. Asia-Pacific Journal of Atmospheric Sciences. https://doi.org/10.1007/s13143-021-00232-7

Gautam, S. (2020). COVID-19: air pollution remains low as people stay at home. Air Quality, Atmosphere \& Health, 2020(13), 853-857.

Gautam, S., \& Hens, L. (2020). COVID-19: Impact by and on the environment, health and economy. Environment, Development and Sustainability, 22, 4953-4954. https://doi.org/10.1007/ s10668-020-00818-7

González, M. D. L. O., Jareño, F., \& Skinner, F. S. (2020). Nonlinear autoregressive distributed lag approach: An application on the connectedness between bitcoin returns and the other ten most relevant cryptocurrency returns. Mathematics, 8(5), 810. https://doi.org/10.3390/math8050810

Green, M. (2020, 03, 13). Air pollution clears in northern Italy after coronavirus lockdown, satellite shows. Retrieved from Reuters: https://www.reuters.com/article/us-health-coronavirus-italy-pollution/airpollution-clears-in-northern-italy-after-coronavirus-lockdown-satellite-shows-idUSKBN2102X4

Greenwood-Nimmo, M., \& Shin, Y. (2013). Taxation and the asymmetric adjustment of selected retail energy prices in the UK. Economics Letters, 121(3), 411-416. https://doi.org/10.1016/j.econlet.2013. 09.020

Guo, Y. R., Cao, Q. D., Hong, Z. S., Tan, Y. Y., Chen, S. D., Jin, H. J., \& Yan, Y. (2020). The origin, transmission and clinical therapies on coronavirus disease 2019 (COVID-19) outbreak-an update on the status. Military Medical Research, 7(1), 1-10. https://doi.org/10.1186/s40779-020-00240-0

Haleem, A., \& Javaid, M. (2020). Effects of COVID 19 pandemic in daily life. Current Medicine Research and Practice, $10(2), 78-79$.

Hashmi, S. M., Chang, B. H., \& Shahbaz, M. (2020). Asymmetric effect of exchange rate volatility on India's cross-border trade: Evidence from global financial crisis and multiple threshold nonlinear autoregressive distributed lag model. Australian Economic Papers. https://doi.org/10.1111/1467-8454. 12194

Hu, C., Liu, X., Pan, B., Chen, B., \& Xia, X. (2018). Asymmetric impact of oil price shock on stock market in China: A combination analysis based on SVAR model and NARDL model. Emerging Markets Finance and Trade, 54(8), 1693-1705. https://doi.org/10.1080/1540496X.2017.1412303

Jones, K. E., Patel, N., \& Levy, M. (2008). Global trends in emerging infectious diseases. Nature, 451, 990-993. https://doi.org/10.1038/nature06536.

Katrakilidis, C., \& Trachanas, E. (2012). What drives housing price dynamics in Greece: New evidence from asymmetric ARDL cointegration. Economic Modelling, 29(4), 1064-1069. https://doi.org/10. 1016/j.econmod.2012.03.029

Kelishadi, R. (2012). Environmental pollution: Health effects and operational implications for pollutants removal. Journal of Environmental and Public health, 1-2.

Kumar, A., Jigyasu, D. K., Kumar, A., Subrahmanyam, G., Mondal, R., Shabnam, A. A., Pinto, M. M. S. C., Malyan, S. K., Chaturvedi, A. K., Khan, S., \& Bhatia, A. (2021). Nickel in terrestrial biota: Comprehensive review on contamination, toxicity, tolerance and its remediation approaches. Chemosphere. https://doi.org/10.1016/j.chemosphere.2021.129996

Kumar, A., \& Sharma, M. P. (2017). Estimation of greenhouse gas emissions from Koteshwar hydropower reservoir, India. Environ Monit Asses, 189(5), 240-249.

Kumar, A., Taxak, A. K., Mishra, S., \& Pandey, R. (2021). Long term trend analysis and suitability of water quality of River Ganga at Himalayan hills of Uttarakhand, India. Environmental Technology \& Innovation. https://doi.org/10.1016/j.eti.2021.101405

Kumar, A., Thanki, A., Padhiyar, H., Singh, N. K., Pandey, S., Yadav, M., \& Yu, Z. G. (2021c). Greenhouse gases emission control in WWTS via potential operational strategies: A critical review. Chemosphere. https://doi.org/10.1016/j.chemosphere.2021.129694

Lokhandwala, S., \& Gautam, P. (2020). Indirect impact of COVID-19 on environment: A brief study in Indian context. Environmental research, 188, 109807. https://doi.org/10.1016/j.envres.2020.109807

Madhav, N., \& Wolfe, N. (2017). Chapter 17 Pandemics: Risks, impacts, and mitigation. In Disease Control Priorities: Improving Health and Reducing Poverty. The International Bank for Reconstruction and Development.

Mohsin, M., Naiwen, L., Zia-UR-Rehman, M., Naseem, S., \& Baig, S. A. (2020a). The volatility of bank stock prices and macroeconomic fundamentals in the Pakistani context: an application of GARCH and EGARCH models. Oeconomia Copernicana, 11(4), 609-636.

Mohsin, M., Naseem, S., Zia-ur-Rehman, M., Baig, S. A., \& Salamat, S. (2020b). The crypto-trade volume, GDP, energy use and environmental degradation sustainability: An analysis of top 20 cryptotrader countries. International Journal of Finance and Economics. https://doi.org/10.1002/ijfe.2442 
Muhammad, S., Long, X., \& Salman, M. (2020). COVID-19 pandemic and environmental pollution: A blessing in disguise? Science of the total environment, 728, 138820. https://doi.org/10.1016/j.scito tenv.2020.138820

Myllyvirta, L. (2020, 02, 19). Analysis: Coronavirus temporarily reduced China's CO2 emissions by a quarter. Retrieved from CarbonBrief: https://www.carbonbrief.org/analysis-coronavirus-has-tempo rarily-reduced-chinas-co2-emissions-by-a-quarter

Omoke, P. C., Opuala-Charles, S., \& Nwani, C. (2020). Symmetric and asymmetric effects of financial development on carbon dioxide emissions in Nigeria: Evidence from linear and nonlinear autoregressive distributed lag analyses. Energy Exploration \& Exploitation, 38(5), 2059-2078. https:// doi.org/10.1177/0144598720939377

Ouattara, B. (2004). Foreign aid and fiscal policy in Senegal (pp. 262-267). Manchester: Mimeo University of Manchester.

Poetzscher, J. (2020, 05, 12). The effect of Covid-19 on India's air quality. Retrieved from The HindusBusiness: https://www.thehindubusinessline.com/opinion/columns/the-effect-of-covid-19-onindias-air-quality/article31564038.ece

Rizou, M., Galanakis, I. M., Aldawoud, T. M., \& Galanakis, C. M. (2020). Safety of foods, food supply chain and environment within the COVID-19 pandemic. Trends in food science \& technology, 102, 293-299. https://doi.org/10.1016/j.tifs.2020.06.008

SanJuan-Reyes, S., Gómez-Oliván, L. M., \& Islas-Flores, H. (2020). COVID-19 in the environment. Chemosphere. https://doi.org/10.1016/j.chemosphere.2020.127973

Sarfraz, M., Qun, W., Hui, L., \& Abdullah, M. (2018). Environmental risk management strategies and the moderating role of corporate social responsibility in project financing decisions. Sustainability, $10,2771$.

Sarfraz, M., Shehzad, K., \& Farid, A. (2020). Gauging the air quality of New York: a non-linear Nexus between COVID-19 and nitrogen dioxide emission. Air Qual Atmos Heal, 13, 1135-1145.

Shah, S. G. M., Sarfraz, M., \& Ivascu, L. (2020). Assessing the interrelationship corporate environmental responsibility, innovative strategies, cognitive and hierarchical CEO: A stakeholder theory perspective. Corporate Social Responsibility and Environmental Management. https://doi.org/10. 1002/csr.2061

Shahzad, S. J. H., Nor, S. M., Ferrer, R., \& Hammoudeh, S. (2017). Asymmetric determinants of CDS spreads: US industry-level evidence through the NARDL approach. Economic Modelling, 60, 211230. https://doi.org/10.1016/j.econmod.2016.09.003

Shakil, M. H., Munim, Z. H., Tasnia, M., \& Sarowar, S. (2020). COVID-19 and the environment: A critical review and research agenda. Science of the Total Environment. https://doi.org/10.1016/j. scitotenv.2020.141022

Sharma, S., Zhang, M., Anshika, Gao, J., Zhang, H., \& Kota, S. H. (2020). Effect of restricted emissions during COVID-19 on air quality in India. Science of the Total Environment, 728, 138878. https:// doi.org/10.1016/j.scitotenv.2020.138878

Shehzad, K., Xiaoxing, L., Arif, M., Rehman, K. U., \& Ilyas, M. (2020). Investigating the psychology of financial markets during COVID-19 Era: A case study of the US and European Markets. Frontiers in Psychology. https://doi.org/10.3389/fpsyg.2020.01924

Shin, Y., Yu, B., \& Greenwood-Nimmo, M. (2014). Modelling asymmetric cointegration and dynamic multipliers in a nonlinear ARDL framework. Festschrift in honor of Peter Schmidt (pp. 281-314). New York: Springer.

Srivastava, S., Kumar, A., Bauddh, K., Gautam, A. S., \& Kumar, S. (2020). 21-Day lockdown in India dramatically reduced air pollution indices in Lucknow and New Delhi, India. Bulletin of environmental contamination and toxicology, 105, 9-17. https://doi.org/10.1007/s00128-020-02895-w

Tobías, A., Carnerero, C., Reche, C., Massagué, J., Via, M., Minguillón, M. C., et al. (2020). Changes in air quality during the lockdown in Barcelona (Spain) one month into the SARS-CoV-2 epidemic. Science of the Total Environment, 726, 138540. https://doi.org/10.1016/j.scitotenv.2020.138540

United Nations. (2018). World urbanization prospects 2018. United Nations.

United Nations. (2019, 06 17). Billion in 2050 and could peak at nearly 11 billion around 2100. Retrieved from United Nations: https://www.un.org/development/desa/en/news/population/worldpopulation-prospects-2019.html

Van, D. T. B., \& Bao, H. H. G. (2019, January). A nonlinear autoregressive distributed lag (NARDL) analysis on the determinants of Vietnam's stock market. In International Econometric Conference of Vietnam. Springer: Cham. pp. 363-376

Verma, A., \& Prakash, S. (2020). Impact of covid-19 on environment and society. Journal of Global Biosciences, 9(5), 7352-7363. 
Wang, G., Zhang, Y., Zhao, J., Zhang, J., \& Jiang, F. (2020a). Mitigate the effects of home confinement on children during the COVID-19 outbreak. The Lancet, 395(10228), 945-947. https://doi.org/10.1016/ S0140-6736(20)30547-X

Wang, P., Chen, K., Zhu, S., Wang, P., \& Zhang, H. (2020b). Severe air pollution events not avoided by reduced anthropogenic activities during COVID-19 outbreak. Resources, Conservation and Recycling, 158, 104814. https://doi.org/10.1016/j.resconrec.2020.104814

Wang, Q., \& Su, M. (2020). A preliminary assessment of the impact of COVID-19 on environment-A case study of China. Science of the Total Environment. https://doi.org/10.1016/j.scitotenv.2020.138915

Wilder-Smith, A., \& Freedman, D. O. (2020). Isolation, quarantine, social distancing and community containment: Pivotal role for old-style public health measures in the novel coronavirus (2019-nCoV) outbreak. Journal of Travel Medicine. https://doi.org/10.1093/jtm/taaa020

Zhang, R., \& Zhang, Y. (2020). NOx Emission Reduction and Recovery during COVID-19 in East China. The Atmosphere, 11(4), 433. https://doi.org/10.3390/atmos11040433.

Zhang, Z., Tsai, S. L., \& Chang, T. (2017). New evidence of interest rate pass-through in Taiwan: A nonlinear autoregressive distributed lag model. Global Economic Review, 46(2), 129-142. https://doi.org/10. 1080/1226508X.2017.1278710

Publisher's Note Springer Nature remains neutral with regard to jurisdictional claims in published maps and institutional affiliations.

\section{Authors and Affiliations}

\section{Muddassar Sarfraz ${ }^{1} \cdot$ Muhammad Mohsin $^{2} \cdot$ Sobia Naseem ${ }^{3} \cdot$ Amit Kumar $^{4}$ (iD}

Muddassar Sarfraz

muddassar.sarfraz@gmail.com

Muhammad Mohsin

mohsinlatifntu@gmail.com

Sobia Naseem

Sobiasalamat4@gmail.com

1 College of International Students, Wuxi University, Wuxi 214105, Jiangsu, China

2 School of Business, Hunan University of Humanities, Science and Technology, Loudi, Hunan, China

3 School of Economics and Management, Shijiazhuang Tiedao University, Shijiazhuang, Heibei, China

4 School of Hydrology and Water Resources, Nanjing University of Information Science and Technology, Nanjing 210044, Jiangsu, PR China 